\title{
CONSERVAÇÃo DE ÁGUA DE COCO VERDE POR FILTRAÇÃO COM MEMBRANA ${ }^{1}$
}

\author{
Márcia Pimentel MAGALHÃES², Flávia dos Santos GOMES ${ }^{3}$, Regina Célia Della MODESTA², \\ Virginia Martins da MATTA ${ }^{3}$, Lourdes Maria Corrêa CABRAL ${ }^{3, *}$
}

\begin{abstract}
RESUMO
A água de coco verde no interior do fruto é estéril, porém, durante a sua extração e envase, podem ocorrer contaminações microbiológicas e alterações bioquimicas, com perda de qualidade do produto e redução do seu valor comercial. Este trabalho teve como objetivo estudar a conservação da água de coco verde através da microfiltração e da ultrafiltração. Para a microfiltração, foram utilizadas membranas com tamanho de poro de $0,1 \mu \mathrm{m}$ e, para a ultrafiltração, membranas com peso molecular de corte de 100,50 e $20 \mathrm{kDa}$. A eficiência do processo foi avaliada através do fluxo permeado e da caracterização microbiológica, fisico-química, bioquímica e sensorial dos produtos obtidos. Não foi observada variação significativa nos parâmetros físico-químicos analisados. A água de coco filtrada apresentou maior luminosidade e menor turbidez. O teor de proteína na água de coco permeada, medida indireta da concentração de enzimas, foi proporcional à porosidade da membrana. A água de coco ultrafiltrada foi envasada em frascos de plástico e armazenada sob refrigeração por 28 dias, sendo avaliada semanalmente. Durante o periodo de armazenamento, as amostras avaliadas mantiveram-se com a coloração clara e adequadas ao consumo, atendendo aos padrões exigidos pela legislação. O produto ultrafiltrado obteve boa aceitabilidade sensorial, tendo sido aprovado por $94 \%$ dos consumidores.

Palavras-chave: microfiltração; ultrafiltração; coco verde; polifenoloxidase; peroxidase; análise sensorial.
\end{abstract}

\section{SUMMARY}

CONSERVATION OF GREEN COCONUT WATER BY MEMBRANE FILTRATION. The green coconut water is sterile inside the nut, but during its extraction and bottling microbiological contamination and biochemical alterations can occur, resulting in quality loss and decrease of its commercial value. The present work aimed at studying the conservation of the green coconut water by microfiltration and ultrafiltration. For microfiltration, a $0.1 \mu \mathrm{m}$ pore size membrane was tested and for the ultrafiltration 100,50 and $20 \mathrm{kDa}$ molecular weight cut off membranes were evaluated. The process efficiency was evaluated by the permeate flux and microbiological, physicalchemical, biochemistry and sensory evaluations. It was not observed significant variation in the physical-chemical parameters. The permeate water presented higher luminosity and lower haze than the original coconut water. The protein content of the permeate coconut water, which is an indirect measure of enzyme concentration, was proportional to membrane porosity. The shelf-life evaluation revealed satisfactory results in relation to the microbiological quality. Among consumers who tasted the ultrafiltrated coconut water, $94 \%$ liked the product.

Keywords: microfiltration; ultrafiltration; green coconut; polyphenoloxidase; peroxidase; sensory analysis.

\section{1 - INTRODUÇÃO}

O coco verde contém cerca de $400 \mathrm{~mL}$ de água que apresenta propriedades nutritivas, possuindo altos teores de potássio, entre outros minerais. É considerada como um repositor de sais e algumas de suas aplicações terapêuticas, como a utilização, na forma de soro oral ou intravenoso, em casos de cólera, problemas intestinais e estomacais têm sido citadas na literatura $[1,6,7,9,11]$.

O sabor da água de coco é doce e levemente adstringente, apresentando um valor de $\mathrm{pH}$ na faixa de 4,0 a 5,6, que é função, principalmente, da variedade e grau de maturação [1, 3, 7]. O produto sofre mudanças na sua composição durante o desenvolvimento do fruto. Além do grau de maturação, outros fatores como variedade, região e época do ano também têm influência sobre as suas características físico-químicas [7, 9].

1. Recebido para publicação em 05/05/2003. Aceito para publicação em 31/01/2005 (001123).

${ }^{2}$ Departamento de Tecnologia de Alimentos, UFRRJ, Antiga Estrada RioSão Paulo, km 47, Seropédica, RJ

3. EMBRAPA - Agroindústria de Alimentos, Av. das Américas, 29501 - Rio de Janeiro, RJ.Email: 1cabral@ctaa.embrapa.br

* A quem a correspondência deve ser enviada.
Dos componentes mais importantes do coco têmse os açúcares que, no início da maturação, apresentam-se na forma de açúcares redutores (glicose e frutose), cujas concentrações alcançam niveis máximos de $5 \%$, próximo ao $6^{\circ}$ e $7^{\circ}$ mês, período em que a quantidade de água também é maior. Com a maturação, a concentração de açúcares redutores diminui em até 1\%, porém são formados açúcares não-redutores (sacarose), sendo, ao final da maturação, o teor de açúcares totais de, aproximadamente, $2 \%[3,6,7]$.

A atividade enzimática na água de coco é um fator de grande relevância, devido às alterações indesejáveis que acarretam, como o desenvolvimento de cor rósea. Há evidências de que a atividade enzimática ocorre com plenitude em frutos com idade de 5 a 7 meses, decrescendo com o amadurecimento [5].

CAMPOS et al. [3] observaram a presença de polifenoloxidase e peroxidase na água de coco verde. Estas enzimas apresentam o máximo de atividade em $\mathrm{pH}$ 6,0 e 5,5 e a temperatura de $25^{\circ} \mathrm{C}$ e $35^{\circ} \mathrm{C}$, respectivamente. Sabe-se que estas enzimas podem estar relacionadas às alterações que ocorrem após a extração da água do fruto [5].

O tempo de estocagem da água de coco depende dos métodos de conservação aplicados. Estes métodos devem objetivar a inibição da atividade enzimática e a 
garantia da qualidade microbiológica após a abertura do fruto, observando-se a manutenção, o quanto possivel, das características sensoriais originais.

A água de coco é tradicionalmente comercializada dentro do próprio fruto, o que envolve diversos problemas relativos ao transporte, armazenamento e perecibilidade do produto. Desta forma, justifica-se o desenvolvimento de técnicas de processamento que possam permitir o envase da água de coco verde, viabilizando a sua comercialização para locais distantes de sua origem, permitindo melhor conservação e menor exigência de espaço para o transporte.

CAMPOS et al. [3] relatam que o tratamento térmico para inativação das enzimas polifenoloxidase e peroxidase, na água de coco verde, só é eficiente acima de $90^{\circ} \mathrm{C}$, mas a partir de 90 segundos de exposição do produto a esta temperatura, já ocorrem problemas sensoriais relacionados às mudanças no aroma e sabor da água de coco. O problema é que, para esta temperatura, a inativação só é completa após 300 segundos de exposição. A redução do $\mathrm{pH}$ não tem sido vista como um método eficiente de inativação enzimática por si só, uma vez que a água de coco apresenta características tamponantes. Observa-se também que a refrigeração não é suficiente para a inibição completa da atividade enzimática na água de coco verde. À temperatura de $5^{\circ} \mathrm{C}$, o percentual de atividade enzimática é de $46 \%$ e $39 \%$ em relação à temperatura ótima, para polifenoloxidase e peroxidase, respectivamente [3]. O emprego de aditivos na inativação enzimática também tem sido pesquisado. Segundo esse autor, o ácido ascórbico foi o mais eficiente na inibição das duas enzimas. O metabissulfito de potássio, na concentração de 15mg/100mL, inibiu 100\% da polifenoloxidase, porém apenas $11 \%$ da atividade de peroxidase.

Como alternativa a estes métodos, pode-se considerar a utilização dos processos de separação com membranas para a remoção das enzimas envolvidas e para a esterilização a frio da água de coco. São processos onde a separação ocorre normalmente à temperatura ambiente e sem mudanças de fase, o que significa uma considerável economia de energia e o não comprometimento da qualidade sensorial dos produtos [12].

Dentre os processos de separação por membranas, a microfiltração, a ultrafiltração e a nanofiltração são os processos mais próximos à filtração clássica. As membranas utilizadas nestes processos são porosas e a seletividade delas é determinada a partir da relação entre o tamanho e a forma dos solutos a serem fracionados e a distribuição de tamanho dos poros existentes na superficie das mesmas. A membrana age como uma peneira molecular. O transporte entre os lados da membrana ocorre pelos poros, por um mecanismo convectivo. O fluxo permeado é diretamente proporcional à diferença de pressão aplicada à membrana. A diferença entre os processos de separação com membranas decorre do tamanho das partículas ou moléculas a serem separadas. Da microfiltração para a nanofiltração, este tamanho diminui e, portanto, o tamanho dos po- ros da membrana utilizada deve ser menor. Com isso, a resistência à transferência de massa oferecida pela membrana é maior e, conseqüentemente, aumenta a diferença de pressão, aplicada à membrana, necessária à permeação [12].

Este trabalho teve como objetivo avaliar a conservação da água de coco verde utilizando a tecnologia de separação por membranas, particularmente a microfiltração e a ultrafiltração.

\section{2- MATERIAL E MÉTODOS}

\section{1 - Matéria-prima}

A água de coco foi extraída de cocos anão verde, com aproximadamente 7 meses de maturação, adquiridos na região de Santa Cruz, município do Rio de Janeiro, RJ.

Os cocos foram adquiridos em lotes de 50 frutos, à medida que os processamentos foram realizados.

\section{2 - Processamento da água de coco verde}

A Figura 1 apresenta um fluxograma do processamento de água de coco por filtração com membranas.

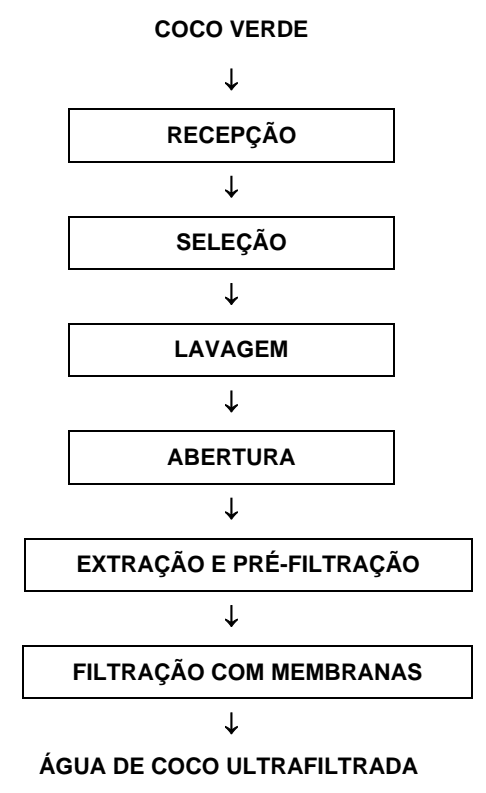

FIGURA 1. Fluxograma do processo de filtração da água de coco verde em membrana

Após seleção visual para descarte dos frutos impróprios, a água de coco era extraída do fruto com auxílio de uma furadeira manual, sendo imediatamente filtrada em peneira de nylon e transferida para o tanque de alimentação do sistema de membranas.

Os experimentos de filtração com membranas foram realizados em um sistema de microfiltração/ultrafiltração da DSS, modelo Lab Unit M20, utilizando membranas planas de poli(sulfona) acondicionadas em um módulo do tipo quadro e placas, que apresentavam uma área de permeação total igual a $0,72 \mathrm{~m}^{2}$. 
O tamanho dos poros das membranas de microfiltração permite a sua determinação visual através de microscópio eletrônico de varredura. Assim, estas membranas são caracterizadas pelo seu tamanho médio de poro, medido em micrômetro. Já as membranas de ultrafiltração apresentam poros menores, sendo impossivel a sua medição visual. Em função disso, estas membranas são caracterizadas pela sua retenção a solutos com pesos moleculares específicos ou peso molecular de corte (cut off). Ou seja, se uma membrana de ultrafiltração apresenta peso molecular de corte igual a $20 \mathrm{kDa}$ significa que ela não permite a permeação de solutos com peso molecular igual ou maior que $20 \mathrm{kDa}$. No presente trabalho, foram utilizadas membranas com tamanho de poro igual a $0,1 \mu \mathrm{m}$, para a microfiltração, e com peso molecular de corte (cut off) igual a $100 \mathrm{kDa}, 50 \mathrm{kDa}$ e $20 \mathrm{kDa}$, para a avaliação do processo de ultrafiltração.

Foram realizadas quatro repetições para cada tipo de membrana, totalizando 16 experimentos. A ordem de realização dos testes foi estabelecida ao acaso. A Figura 2 apresenta um esquema do sistema de filtração com membranas.

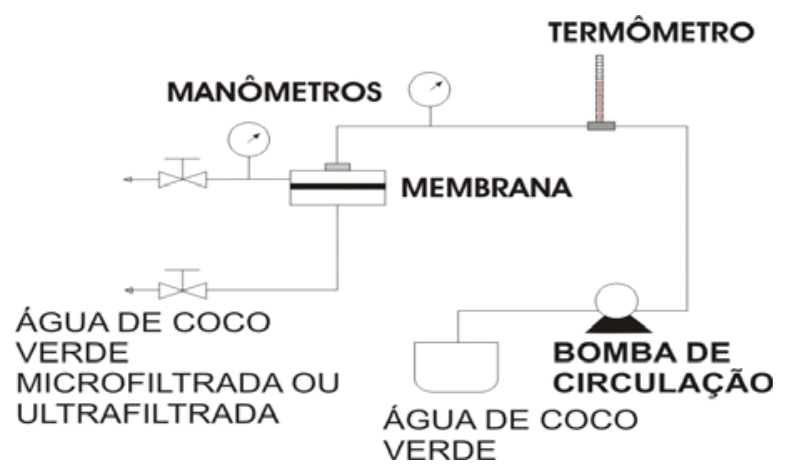

FIGURA 2. Desenho esquemático do sistema de microfiltração/ultrafiltração.

O processo foi realizado em regime de batelada com recirculação da corrente não-permeada, sendo o permeado recolhido continuamente. O fluxo permeado $(\mathrm{J})$ foi avaliado em intervalos que dependiam da porosidade da membrana em teste, através da medida do tempo necessário $(\Delta \mathrm{t})$ para a permeação de um determinado volume $(\mathrm{V})$, conforme a equação a seguir:

$$
J=\frac{V}{A * \Delta t}
$$

sendo A, a área de permeação do módulo, neste caso igual a $0,72 \mathrm{~m}^{2}$.

Todos os experimentos foram realizados a $25^{\circ} \mathrm{C}$. A diferença de pressão aplicada à membrana foi igual a 2bar. A vazão de circulação da alimentação também foi mantida constante e igual a 480L/h.

Foram coletadas amostras da água de coco verde que alimentava o sistema de membranas (alimentação) e, ao final do processo, amostras da água permeada (permeado) e da não permeada (retido). A água de coco permeada foi envasada em frascos de plástico e armazenada sob refrigeração por 28 dias, sendo avaliada semanalmente.

Para avaliação da eficiência de cada processo foram realizadas análises microbiológicas (contagem de bolores e leveduras, bactérias mesófilas, coliformes totais e fecais e presença de Salmonella) [13] e físico-químicas (teor de sólidos solúveis e teor de sólidos totais, acidez total titulável, $\mathrm{pH}$ ) [2].

A determinação do teor de proteína, medida indireta da concentração de enzimas, foi determinada através do Método de Lowry, o qual baseia-se na utilização de albumina bovina como padrão. A absorbância das amostras foi lida a 660nm, utilizando-se um espectrofotômetro LAMBDA 10, fabricado pela Perkin Elmer. Para cada amostra foram realizadas duplicatas, da qual obteve-se a média como resultado final de proteína total [8].

A atividade enzimática foi determinada através do acompanhamento da reação com catecol por espectrofotometria, segundo metodologia sugerida por CAMPOS et al. [3].

A determinação da cor foi realizada através da análise de transmitância no colorímetro fotoelétrico $S \& M$ Colour Computer modelo SM-4-CH da Suga, no sistema Hunter. Os parâmetros considerados foram: luminosidade (L), que mede a intensidade de branco e varia de 100, para superficies perfeitamente brancas, até zero, para o preto, e a turbidez (haze). As amostras, de $30 \mathrm{~mL}$ cada, foram dispostas em placa de Petri com $5 \mathrm{~cm}$ de diâmetro e $2 \mathrm{~cm}$ de altura.

\section{3 - Aceitabilidade de água de coco processada}

Uma vez definida a melhor condição de processamento, a aceitabilidade da água de coco ultrafiltrada foi avaliada através da escala hedônica de 7 pontos (7 = "gostou muito" a 1 = "desgostou muito"). O produto foi servido à temperatura de $12^{\circ}$ a $15^{\circ} \mathrm{C}$, em copo descartável de $50 \mathrm{~mL}$, em cabine individual sob luz vermelha. O teste foi realizado com 100 consumidores de ambos os sexos [10].

\section{3- RESULTADOS E DISCUSSÃO}

A Figura 3 apresenta os resultados referentes ao comportamento do fluxo permeado de água de coco verde durante os processos de filtração nas membranas com tamanho de poro equivalente a 0,1 $\mu \mathrm{m}$ e cut off de 100, 50 e 20kDa. Para cada membrana é apresentada a curva referente à média das quatro repetições realizadas.

Observou-se, em todos os casos, a ocorrência do clássico fenômeno de fouling, evidenciado pela queda do fluxo permeado ao longo do processo. O fouling é o resultado do aumento da concentração de solutos na superficie da membrana, do entupimento de poros e também da adsorção de moléculas no material da membrana. Todos estes fatores contribuem para aumentar a resistência à transferência de massa através da mem- 
brana, quer seja pela redução da porosidade (entupimento, adsorção), quer seja pela polarização de concentração na superfície da membrana, devido ao acúmulo de solutos [14].

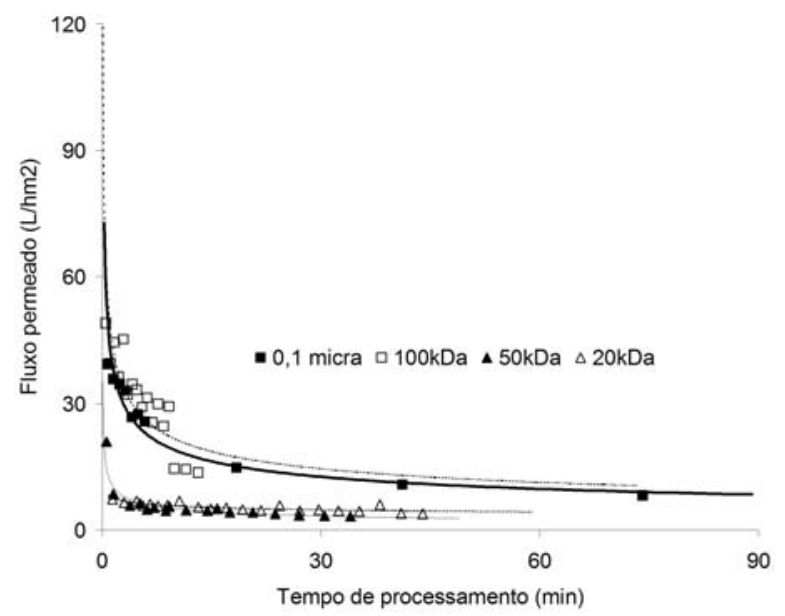

FIGURA 3. Fluxo permeado médio de água de coco verde durante os processos de filtração nas membranas com tamanho de poro equivalente a $0,1 \mu \mathrm{m}$, e cut off de 100 , 50 e $20 \mathrm{kDa}$

Neste trabalho, as membranas utilizadas não foram previamente caracterizadas quanto a sua distribuição de tamanho de poros na superficie das mesmas. Apenas a permeabilidade a água era avaliada antes e após cada processo, como um meio de avaliar o estado de limpeza e integridade da membrana.

De acordo com o fabricante, as membranas de $0,1 \mu \mathrm{m}$ (microfiltração) e de $100 \mathrm{kDa}$ (ultrafiltração), como também as de 50 e 20kDa não diferem muito entre si, apresentando as duas primeiras, permeabilidade de água acima de $150 \mathrm{Lh} / \mathrm{m}^{2}$, e as duas últimas, permeabilidade em torno de $60 \mathrm{Lh} / \mathrm{m}^{2}$. Tal fato pode explicar a pouca variação entre os fluxos permeados das membranas de $0,1 \mu \mathrm{m}$ e $100 \mathrm{kDa}$ e das membranas de $50 \mathrm{kDa}$ e $20 \mathrm{kDa}$.

Observou-se, através de uma análise comparativa, que o fluxo permeado, nas quatro repetições do processo de microfiltração, foi inferior ao fluxo obtido quando a membrana de ultrafiltração de cut off de 100kDa foi utilizada. Este comportamento pode ser explicado novamente pelo fenômeno do fouling. A membrana de microfiltração apresenta poros com tamanho tal que, muitas vezes, algumas moléculas ou partículas permeiam através dos poros da interface membrana-alimentação, mas ficam retidas no interior dos mesmos, causando o fenômeno muitas vezes irreversível conhecido como entupimento ou bloqueamento dos poros. Neste caso, a porosidade da membrana diminui irreversivelmente, resultando numa queda maior de fluxo. Este fenômeno não ocorre da mesma maneira na membrana de ultrafiltração, pois a sua distribuição superficial de tamanho de poros não permite que as moléculas ou partículas entrem na sua estrutura. O fenômeno do bloqueamento é minimizado, embora a polarização de concentração devido ao acúmulo na superficie seja maior. Este acúmulo, entretanto, é reversivel e pode ser minimizado, se as condições de escoamento forem favorecidas sobre a superficie da membrana.

Para um melhor entendimento da eficiência do processo com membrana na filtração da água de coco e para minimizar o efeito da variação do lote de matériaprima foi definida a Redução Percentual, Rp, conforme a equação 2 :

$$
R_{P}=\frac{A-P}{A} \times 100
$$

sendo A, o valor do parâmetro (por exemplo $\mathrm{pH}$ ou teor de proteína) na água de coco verde que era alimentada ao sistema e $\mathrm{P}$ o valor deste mesmo parâmetro na água de coco permeada.

Nas Tabelas 1 e 2 são apresentados, respectivamente, os resultados das avaliações físico-químicas e de cor instrumental nos diferentes processamentos. Conforme esperado, o teor de sólidos solúveis, assim como os valores de acidez total titulável e pH não apresentaram diferenças significativas entre os processamentos, quando comparados aos seus valores nas respectivas alimentações. Cabe ressaltar que os valores mais baixos dos teores de sólidos solúveis e de sólidos totais no permeado, em relação aos da alimentação, podem ser conseqüência do acúmulo de material retido na superficie da membrana, que pode atuar como uma resistência adicional a transferência de massa, tornando o processo mais seletivo.

TABELA 1. Caracterização físico-química da água de coco original e do permeado dos diferentes processamentos em escala piloto

\begin{tabular}{|c|c|c|c|c|c|c|c|c|c|c|c|c|}
\hline & \multicolumn{3}{|c|}{$\mathrm{pH}^{*}$} & \multicolumn{3}{|c|}{$\begin{array}{l}\text { Acidez (\% ácido } \\
\text { cítrico)* }\end{array}$} & \multicolumn{3}{|c|}{$\begin{array}{l}\text { Teor de sólidos } \\
\text { solúveis ( }{ }^{\circ} \text { Brix) }{ }^{\star}\end{array}$} & \multicolumn{3}{|c|}{$\begin{array}{l}\text { Teor de sólidos } \\
\text { totais }(\% \mathrm{p} / \mathrm{p})^{\star}\end{array}$} \\
\hline & A & $\mathrm{P}$ & $\mathrm{Rp}$ & $A$ & $P$ & $\mathrm{Rp}$ & A & $\mathrm{P}$ & $\mathrm{Rp}$ & A & $\mathrm{P}$ & $\mathrm{Rp}$ \\
\hline $0,1 \mu \mathrm{m}$ & 5,00 & 5,00 & 0,0 & 0,08 & 0,08 & 0,0 & 4,78 & 4,58 & 4,2 & 5,45 & 5,05 & 7,3 \\
\hline $100 \mathrm{kDa}$ & 5,13 & 5,13 & 0,0 & 0,10 & 0,10 & 0,0 & 5,28 & 5,20 & 1,4 & 6,05 & 6,23 & 2,9 \\
\hline $50 \mathrm{kDa}$ & 5,18 & 5,23 & $-1,0$ & 0,10 & 0,10 & 0,0 & 4,90 & 4,73 & 3,6 & 5,53 & 5,15 & 6,8 \\
\hline $20 \mathrm{kDa}$ & 4,93 & 4,93 & 0,0 & 0,08 & 0,08 & 0,0 & 5,00 & 4,68 & 6,5 & 5,53 & 5,20 & 5,9 \\
\hline$F_{\text {processo }}$ & & & - & & & - & & & $1,27^{\text {ns }}$ & & & $0,08^{\text {ns }}$ \\
\hline
\end{tabular}

*valores médios de 4 repetições; $A=$ AlimentaçãoP $=$ Permeado Rp $=$ Redução

ns: não significativo $(\mathrm{p}<0,05)$

TABELA 2. Caracterização instrumental de luminosidade e da turbidez da água de coco original e do permeado dos diferentes processamentos em escala piloto

\begin{tabular}{llrrrrr}
\hline Membrana & \multicolumn{3}{c}{ Luminosidade* $^{*}$} & \multicolumn{3}{c}{ Turbidez* $^{*}$} \\
& $\mathrm{~A}$ & $\mathrm{P}$ & $\mathrm{Rp}$ & \multicolumn{1}{c}{$\mathrm{A}$} & $\mathrm{P}$ & $\mathrm{Rp}$ \\
\hline $0,1 \mu \mathrm{m}$ & 96,6 & 98,7 & $-2,2$ & 10,0 & 1,2 & 88,3 \\
$100 \mathrm{kDa}$ & 96,1 & 100,3 & $-4,3$ & 13,3 & 0,9 & 93,0 \\
$50 \mathrm{kDa}$ & 98,5 & 99,7 & $-1,2$ & 7,8 & 3,2 & 59,4 \\
$20 \mathrm{kDa}$ & 96,5 & 99,8 & $-3,4$ & 8,6 & 1,6 & 82,0 \\
F & & & $0,34^{\mathrm{ns}}$ & & & $0,72^{\mathrm{ns}}$
\end{tabular}

*valores médios de 4 repetições; ns: não significativo; * significativo $(\mathrm{p}<0,05)$ $\mathrm{A}=$ alimentaçãoP $=$ permeado $\mathrm{Rp}=$ Redução percentual Luminosidade $(0=$ preto e $100=$ branco $)$ 
Pode-se observar que os valores de luminosidade da água permeada aumentaram em relação aos da alimentação. A redução na turbidez, com conseqüente aumento na luminosidade, é conseqüência da retenção, pela membrana, de sólidos em suspensão. A porosidade da membrana utilizada não alterou significativamente a redução percentual da turbidez ou a da luminosidade.

O teor de proteína foi interpretado como uma medida indireta da concentração enzimática. Verificou-se uma tendência decrescente da concentração de proteína nos permeados em função da menor porosidade da membrana utilizada (Tabela 3). Como as membranas de 50 e $20 \mathrm{kDa}$ foram as que apresentaram os maiores indices de retenção percentual de proteína, os permeados obtidos nestas membranas foram analisados quanto à atividade das enzimas peroxidase e polifenoloxidase (Tabela 4).

TABELA 3. Teor de proteína da água de coco original e do permeado dos diferentes processamentos em escala piloto

\begin{tabular}{lccc}
\hline \multicolumn{1}{c}{ Membrana } & \multicolumn{3}{c}{ Teor de proteína (g/l) } \\
& $\mathrm{A}$ & $\mathrm{P}$ & $\mathrm{R}_{\mathrm{p}}(\%)$ \\
\hline $0,1 \mu \mathrm{m}$ & 1,24 & 0,94 & 24 \\
$100 \mathrm{kDa}$ & 1,01 & 0,76 & 25 \\
$50 \mathrm{kDa}$ & 1,27 & 0,79 & 38 \\
$20 \mathrm{kDa}$ & 1,21 & 0,69 & 43 \\
\hline
\end{tabular}

*valores médios de 4 repetições; $A$ = AlimentaçãoP $=$ Permeado Rp = Redução percentual

TABELA 4. Atividade da polifenoloxidase (POF) e da peroxidase $(\mathrm{PEO})$ na água de coco original e no permeado

\begin{tabular}{lcccccc}
\hline Membrana & \multicolumn{3}{c}{ POF (U/mL) } & \multicolumn{3}{c}{ PEO (U/mL) } \\
\hline \multirow{2}{*}{$50 \mathrm{kDa}$} & $\mathrm{A}$ & $\mathrm{R}$ & $\mathrm{P}$ & $\mathrm{A}$ & $\mathrm{R}$ & $\mathrm{P}$ \\
$20 \mathrm{kDa}$ & 1,23 & 1,67 & 0,48 & 1,79 & 5,80 & nd \\
& 1,90 & 6,30 & 0,44 & 1,40 & 4,11 & nd \\
\hline
\end{tabular}

$\mathrm{A}=$ AlimentaçãoR $=$ Retentado $\mathrm{P}=$ Permeado nd: não detectado

DUARTE et al. [4] determinaram, por cromatografia por gel filtração (Superdex), o peso molecular das enzimas oxidativas presentes na água de coco verde de frutos provenientes da mesma região que os frutos utilizados no presente trabalho. Foram obtidos os seguintes pesos moleculares: $73,8 \mathrm{kDa}$ para a polifenoloxidase e, para a peroxidase, o valor estimado foi de $49,2 \mathrm{kDa}$. Tais resultados confirmam o comportamento observado no processo de ultrafiltração com as membranas de 20 e $50 \mathrm{kDa}$.

Todas as amostras de água de coco microfiltradas e ultrafiltradas apresentaram-se em condições de esterilidade comercial à saída da linha de permeado (Tabela 5). A água de coco ultrafiltrada e armazenada sob refrigeração mantiveram a coloração clara, característica da água de coco, e apresentaram qualidade microbiológica adequada ao consumo durante os 28 dias de armazenamento.
TABELA 5. Avaliação microbiológica da água de coco processada nas diferentes membranas.

\begin{tabular}{lcccc}
\hline Membranas & 0,1 micra & $100 \mathrm{kDa}$ & $50 \mathrm{kDa}$ & $20 \mathrm{kDa}$ \\
\hline CPP & $1,0 \times 10^{1}$ & $1,5 \times 10^{1}$ & $1,4 \times 10^{1}$ & $1,0 \times 10^{1}$ \\
$\mathrm{CFL}$ & $1,0 \times 10^{1}$ & $4,5 \times 10^{1}$ & $8,7 \times 10^{1}$ & $1,1 \times 10^{1}$ \\
$\mathrm{CCT}$ & $<3$ & $<3$ & $<3$ & $<3$ \\
$\mathrm{CCF}$ & $<3$ & $<3$ & $<3$ & $<3$ \\
Salmonella (em 30g) & Ausência & Ausência & Ausência & Ausência
\end{tabular}

CBM: contagem de bactérias mesófilas, CFL: contagem de fungos filamentosos e leveduras, CCT: contagem de coliformes totais, CCF: contagem de coliformes fecais.

Como não houve diferença significativa nas características físico-químicas das águas permeadas nas diferentes membranas, a água de coco ultrafiltrada na membrana com cut off de $20 \mathrm{kDa}$ foi selecionada para o teste de aceitabilidade. Dos consumidores que provaram a água de coco processada, 50\% gostaram muito, $30 \%$ gostaram regularmente, $14 \%$ gostaram ligeiramente e $1 \%$ não gostou nem desgostou (Figura 4). Do total dos consumidores que provaram o produto, $94 \%$ gostaram do mesmo (Figura 5).
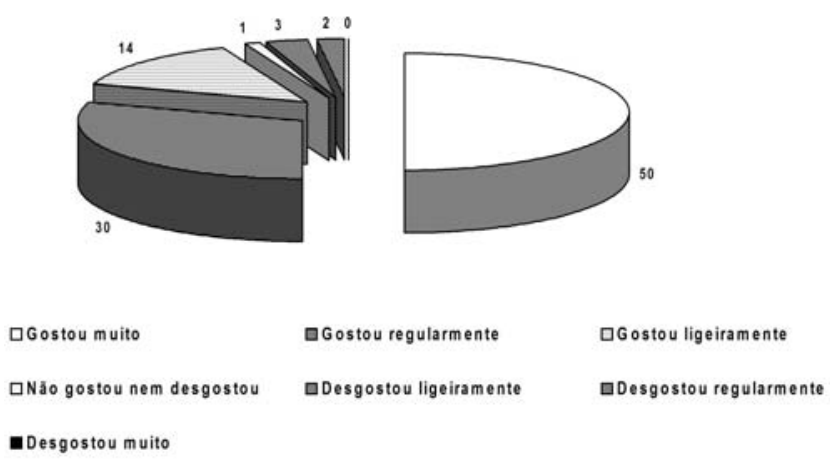

FIGURA 4. Aceitabilidade estratificada da água de coco processada

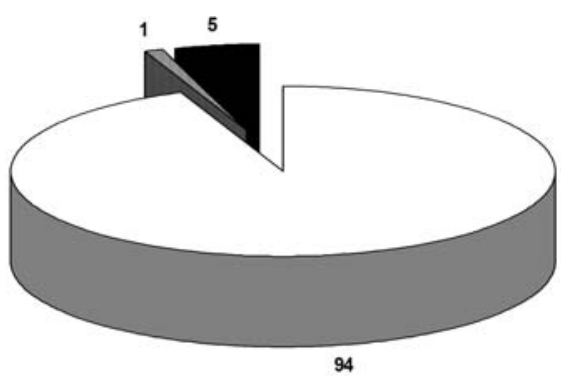

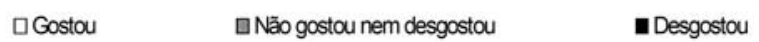

FIGURA 5. Aceitabilidade da água de coco processada

Ao se avaliar o que os consumidores mais gostaram na água de coco, pode-se destacar o sabor $(22 \%$ dos consumidores) e a doçura (15\%). Com relação ao que mais desgostaram, $71 \%$ não indicaram atributo algum. 
Em relação à intensidade de doçura, 20\% consideraram muito doce, $51 \%$, bom, e $29 \%$ acharam pouco doce (Figura 6). Quanto à intenção de compra, 68\% dos consumidores comprariam o produto, $23 \%$ talvez comprassem e 9\% não comprariam (Figura 7).

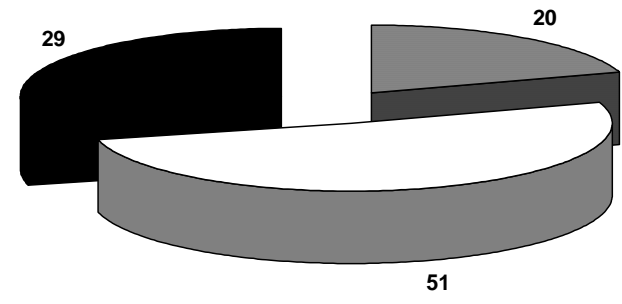

$\square$ muito doce

$$
\square \text { bom }
$$

pouco doce

FIGURA 6. Intensidade de doçura da água de coco processada

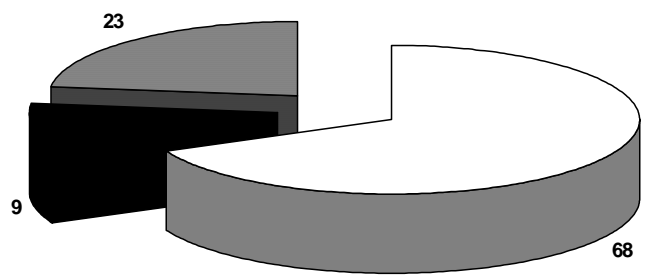

口compraria

—não compraria

$\square$ tavez compraria

FIGURA 7. Intenção de compra da água de coco processada

\section{4 - CONCLUSÕES}

A partir da observação dos resultados dos processamentos com membranas de diferentes tamanhos de poros, pode-se concluir que:

- as características físico-químicas da água de coco permeada permaneceram inalteradas se comparadas às da água de coco original (alimentação);

- a turbidez da água de coco foi reduzida significativamente após o processo de filtração;

- os processamentos com membranas foram eficazes na redução do teor de proteínas. Tal redução foi função da porosidade da membrana utilizada;
- $\quad$ em relação à qualidade microbiológica, todas as amostras apresentaram esterilidade comercial à saída do permeado;

- a água de coco processada teve uma aceitabilidade de $94 \%$ dos consumidores.

\section{5 - REFERÊNCIAS BIBLIOGRÁFICAS}

[1] ANZALDO, F.E.; KINTANAR, Q.L.; RECTO, P.M.; VELASCO, R.U.; DE LA CRUZ, F. and JACALNE, A. Coconut water as intravenous fluid. PJCS, v. X, n. 1, p. 31-43, 1985.

[2] AOAC. American Official of Analytical Chemists. Official methods of analysis of AOAC international. 17. ed. Washington, 1997.

[3] CAMPOS, C.F. SOUZA, P.E.A.; COELHO, J.V.; GLÓRIA, M.M.B.A. Green coconut water quality. Journal of Food Processing and Preservation, v. 20, p. 487-500, 1996.

[4] DUARTE, A.C.P.; RODRIGUES, S.L.C.; COELHO, M.A.; LEITE, S.G.F. Separação das enzimas peroxidase e tirosinase na água de coco por HPLC. In: Anais do III Simpósio Latino Americano de Ciência de Alimentos, Campinas, 1999. Livro de Resumos. P. 73.

[5] GALEAZZI, M.A.M. Comportamento das polifenoloxidases em alimentos. Arch. Latinoam. Nut., v. 34, n. 2, p. 2609-289, 1984.

[6] JASPER, C.W. Coconuts: production, processing, products. 2.ed. New York: Avi Van Nostrand Reinhold, 1979.

[7] JAYALEKSHMY,A.; ARUMAGHAN,C; NARAYNAN, S.; MATHEW, A.G. Changes in the chemical composition of coconut water during maturation. J. Food Sci. Technol., v.23, n. 4, p. 203-207, 1984.

[8] LOWRY, O.H., ROSEBROUGH, N.H., FARR, A L.; RANDALL, R.J. Protein measurement with the folin phenol reagent. J. Biol. Chem., v. 193, p. 265, 1951.

[9] MACIEL, M.I.; OLIVEIRA, S.L.; SILVA, I.P. Effects of different storage conditions on preservation of coconut (Cocos nucife) water. Journal of Food Processing and Preservation, v. 16, p. 13-22, 1992.

[10] MEILGAARD, M.; CIVILlE, G.V.; CARR, B.T. Sensory evaluation techniques. Boca Raton, CRC Press, 2 v., 1991. 354p.

[11] MONTENEGRO, H.M. Coconut oil and its byproducts. Journal Amer. Oil Chem. Soc., v. 62, n. 2, p. 259-261, 1985.

[12] MULDER, M. Basic principles of membrane technology. S.1.: Kluwer Academic Publishers, 1987.

[13] SIQUEIRA (1985) SIQUEIRA, R.S. Manual de Microbiologia de Alimentos. Rio de Janeiro. EMBRAPA. 159p. 1995.

[14] VLADISAVLJEVI, G.T.; VUKOSAVLJEVI, P.; BUKVI, B. PERMEATE.Flux and fouling resistance in ultrafiltration of depectinized apple juice using ceramic membranes, Journal of Food Engineering (2003) in press. 